\title{
REFLECTIONS
}

\section{Journey During Acute Ischemic Stroke: A Physician's Experience}

\author{
Low Chen Hoong, FRCR ${ }^{1}$ \\ Vijay K. Sharma, $M D^{2}$ \\ 'Medi-Rad Associates Radiology Clinic, \\ Singapore \\ ${ }^{2}$ Division of Neurology, National \\ University Hospital, Singapore
}

Conflicts of interest: none reported

\section{CORRESPONDING AUTHOR}

Vijay K. Sharma, MD

Division of Neurology, National

University Hospital

Singapore 119074

drvijay@singnet.com.sg

\begin{abstract}
Acute ischemic stroke is a potentially devastating condition. What follows is a true narration of the experience of a doctor-patient during his treatment for acute ischemic stroke and how the experience changed him. Described is the temporal sequence of events, starting from home to infusion of tissue plasminogen activator, which, when coupled with a multimodal therapeutic approach, resulted in an excellent clinical recovery.
\end{abstract}

Ann Fam Med 2010;8:265-267. doi:10.1370/afm.1120.

I

(L.C.H.) am 57 years old and a practicing radiologist. On the morning of August 29, 2008, having finished reading an article on the assess-

ment of cerebral perfusion with arterial spin labeling and its potential applications in patients with cerebrovascular diseases, I waited for my wife to come back from her fitness class. I was feeling a bit lethargic and thought I would take a short nap. Before I could sleep, my wife returned, accompanied by our 7-year old granddaughter. My granddaughter insisted on playing with me while my wife went to prepare coffee. I felt that something was wrong but could not make it out, so I lay down on the floor beside the coffee table. Lying on the cold marble floor was one of my ways to relax despite my wife's dislike of this habit.

I do not know whether I dozed off. I was startled by my wife calling from the kitchen, where she saw something on the ceiling and wanted me to check it out. I tried to get up but could not. I tried to pull myself up by holding the leg of the coffee table on my right side, but the only thing I succeeded in doing was pulling the heavy coffee table toward me. My body, especially the left side, was not listening to me. I could not make out what was wrong. I had seen hundreds of stroke patients while performing their brain scans, and the thought, "Am I having a stroke?" crossed my mind. Denial and self-confidence overruled this thought. I had a firm belief that I could not have a stroke, so instead of going to help my wife in the kitchen, I called her to help me. She tried to help me stand but did not have enough strength to do so.

Although past illnesses and deaths of close friends and relatives had prompted us to discuss the uncertainties and fragility of human life, we never discussed what to do if such serious events happened to one of us. My wife and I looked at each other with confusion, anxiety, and disbelief. My wife looked worried as she saw my face drooping to one side. I tried to reassure her that I was just feeling a bit tired and would be all right after some rest. She told me, however, that I might be having a stroke and immediately called for an ambulance. That frightened me, but my mind was totally blocked. I also heard her talking to my son-in law, who was an anesthesiologist in a nearby tertiary care hospital. As she has for the past 40 years, my wife maintained her calm and appeared confidently prepared for the battle ahead. She sat beside me and reassured me repeatedly that 
everything would be all right. I felt stuck and helpless. That was when I was convinced I was having a stroke. It's amazing what a minute can do.

I remember the arrival of the ambulance and the quick assessment by the paramedics. They asked me a couple of questions. I knew the answers but could not come out with appropriate words and mumbled some unintelligible answers, even amusing myself. I realized, however, that something serious with rapid deterioration was happening. Although the thought of living a paralyzed life was frightening, I was unable to gather mental strength, and I felt more relaxed than scared. Everything was becoming cloudy and too complicated for me. I was losing connections with my surroundings.

I cannot remember my journey to the hospital. I vaguely recall the emergency department as a brightly lit room and many people attending to me. My mind was not able to keep pace with the activity around me. Although I had been working with computed tomographic (CT) scanners for decades, I could not recognize the CT equipment when my own head was being scanned. Despite being an optimist, I had, perhaps, given up.

The next thing I could feel was pressure on my right temple, and I felt like I was getting up after a long sleep. I was unable to move my left hand but heard some hissing sounds from a machine. As I looked up, a neurologist (V.K.S.) was performing transcranial Doppler (TCD) on me and explaining it to his colleagues. He was talking about the CLOTBUST study, where TCD was shown to enhance the effect of intravenous thrombolysis. ${ }^{1}$ He appeared excited and was explaining that the artery in my brain had recanalized within 25 minutes of starting tissue plasminogen activator (TPA). He asked me to move my left hand and leg. Everyone around me appeared happy. Someone asked me to lift my left leg and hand. I was still unable think analytically, but the curiosity and disbelief in their eyes was stimulating, and I wanted to do it again and again.

During the next 5 minutes or so, things changed faster. While my mind was racing to remember and analyze what had happened to me, my thoughts were disturbed by my inability to see my wife despite hearing her voice. My neurologist asked my wife to stand by my right side, as I was blind on my left side. He explained that a blood clot had occluded my right internal carotid artery in the brain, causing severe weakness and hemianopia on my left side. I was told that TPA administration had recanalized my artery, and I had already recovered "remarkably." Yes, I could move my left leg, but I still struggled in moving the left hand. My wife told me that she had consented to TPA therapy after being told the possible benefits, expected side-effects, and the past experience of the center. ${ }^{2}$
The doctors and nurses around me appeared more relaxed. I heard that TPA infusion would finish in another 20 minutes. By now, I was fully back in the real world. Thoughts were crossing my mind about the future. Would I recover? How much? Would I walk again? Would I work again?

My chain of thoughts was broken when I heard my neurologist tell his colleague that he was not happy with the frequent emboli on TCD monitoring and asked someone to bring the carotid duplex machine. I heard him say that lesions amenable to treatment could be reliably diagnosed with TCD and carotid duplex. ${ }^{3}$ Within the next 10 minutes, a sonogram revealed a mobile thrombus in my right internal carotid artery in the neck. He showed the ultrasound images to my wife and explained that the carotid thrombus could dislodge and block my intracranial arteries again. The worst was not over yet!

Suddenly, the activities around me increased, and I heard my neurologist talking to someone on the telephone about me. I was told that the clot in my carotid artery in the neck was "fresh and mobile," and that arrangements were being made to remove it with an endovascular approach. The plan was explained to my wife and me. I was fully aware, and being a radiologist, I knew the procedure and associated risks. I thought for a moment about whether I should agree to the proposed intervention, especially when I had recovered almost completely with TPA. Would I survive the procedure? On my wife's face, I could see a confident look, but with a tinge of nervousness and uncertainty in her eyes. I decided to leave the decision to her. Although I had made all decisions about my family's health care in the past, I now wished my wife to take the responsibility. She and I felt comforted upon learning that the interventionalist was my close friend.

TPA was finished and arrangements were made for my transfer to the interventional suite. During my transfer from the trolley to the angiography table, I realized that my neurologist's apprehensions about the carotid thrombus were correct as the strength in my left hand and leg started worsening. My interventionalist friend greeted me and reassured me that everything would be fine. He opted for doing the procedure under general anesthesia, and my son-in-law would be my anesthetist. Doctors often feel uncomfortable about treating their own family members, so I called my son-in-law and asked him whether he was comfortable with the arrangement. I assured him of my faith in his capabilities.

Next I found myself in the intensive care room with an uncomfortable endotracheal tube in my throat. I could feel my limbs and move them freely. I knew that I had survived the massive stroke. The endotracheal 
tube was removed soon thereafter, and I could talk normally. I was taken for a CT scan, and the excited and satisfied look on my neurologist's face told the result — a small infarct without any clinical deficits. I was able to walk again and moved to the general ward.

In a short span of 24 hours, I had been to 6 different locations in the hospital: emergency department, CT scan room, neurology high-dependency unit, interventional suite, intensive care unit, and general ward. I was discharged from the hospital the next day, walking and helping my wife carry some of my things. I returned to my busy schedule within a week.

I have fallen ill many times in my life. Although this illness lasted only 3 days, I felt the real experience of being a patient. In less than 24 hours, I lived the life of a paralyzed, dependent, and defenseless man, then became myself again.

In the past in my role as a radiologist, I was confined to looking at the scans of patients and sending reports without any emotions. This experience has changed my attitudes toward my patients. Now, I try to talk at least briefly with them, explain the test, and reassure them and their families to the best of my abilities. I feel that a few words of encouragement could make vast differences in patients' fights with their diseases and boost the morale of their family members.

I have changed in other ways as well. I am reminded of the developments in neurological sciences since I completed my medical officer's training 20 years ago. I realize the fragility of life. I am humbled by the collaborative and concerted efforts of all specialists, nurses, and other paramedical staff involved in my short but intensive care. This experience has made me a stronger person with a staunch belief in modern medicine. It has reaffirmed my commitment toward my patients and rejuvenated my attitude toward life.

I have been gifted with a second chance to contribute my part toward reducing human suffering. We need to be reminded of our place in life and of just how fleeting life is. Life is fragile, and we should never take it for granted.

To read or post commentaries in response to this article, see it online at http://www.annfammed.org/cgi/content/full/8/3/265.

Key words: Acute ischemic stroke; Intravenous thrombolysis; transcranial Doppler; mechanical embolectomy

Submitted June 29, 2009; submitted, revised, September 6, 2009; accepted October 1, 2009.

Acknowledgment: This account of my (Low Chen Hoong) experience of acute ischemic stroke is based on my recollections and interpretations. My account includes considerable input from my neurologist (Vijay K. Sharma), who managed my case and clarified some of the queries, both during my hospital stay and after discharge.

\section{References}

1. Alexandrov AV, Molina CA, Grotta JC. Ultrasound-enhanced systemic thrombolysis for acute ischemic stroke. $N$ Engl J Med. 2004;351(21):2170-2178.

2. Sharma VK, Tsivgoulis G, Tan JH, Ong BK, Chan BP, Teoh HL. Intravenous thrombolysis is feasible and safe in multiethnic Asian stroke patients in Singapore. Int J Stroke. 2009;4(5)320-321.

3. Chernyshev OY, Garami Z, Calleja S. Yield and accuracy of urgent combined carotid/transcranial ultrasound testing in acute cerebral ischemia. Stroke. 2005;36(1):32-37. 